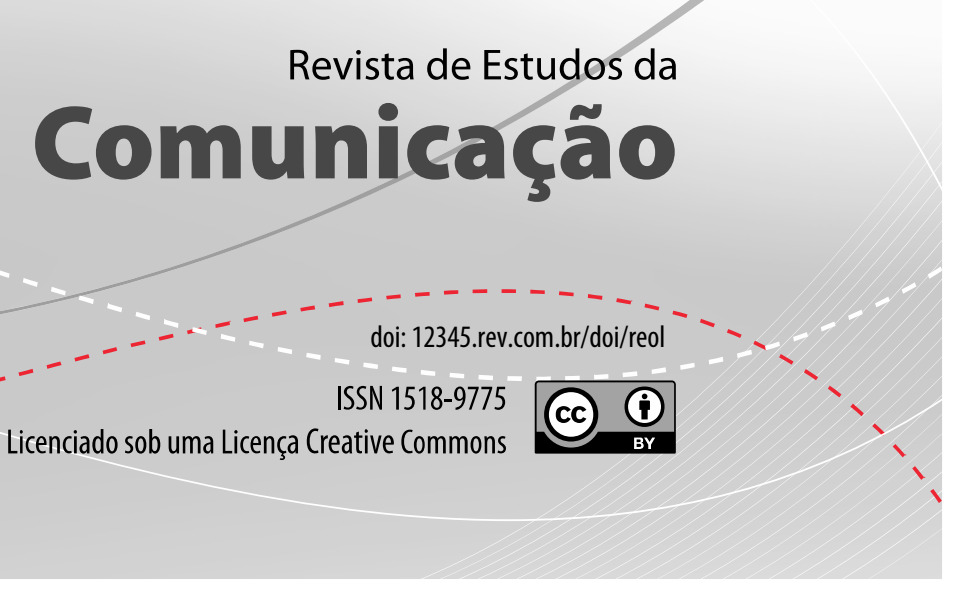

\title{
Comunicação, arte e cultura: a mediação midiática nos modos de ver e produzir saberes artísticos culturais na cidade Curitiba
}

\author{
Communication, art and culture: the media mediation in ways of \\ seeing and producing artistic cultural knowledge in the city Curitiba
}

\section{Adalgisa A. de Oliveira Gonçalves}

Doutora em Ciência Humanas pela Universidade Federal de Santa Catarina (UFSC), professora da Escola de Comunicação e Artes da Pontifícia Universidade Católica do Paraná (PUCPR), Curitiba, PR - Brasil, e-mail: adalgisa.oliveira@pucpr.br

\section{Resumo}

Este artigo visa comunicar o resultado de uma pesquisa sobre a influência da mídia nos modos de ver e produzir saberes artísticos culturais em Curitiba, no Paraná. Parte-se da análise do jornal Gazeta do Povo como mídia preferencial para a pesquisa e fonte de abordagem com os informantes e interlocutores desta pesquisa. Os conceitos de comunicação, arte e cultura são trabalhados na perspectiva de compreender o entrelaçamento que se dá por meio da mediação midiática, assim como compreender os processos de significação, de apropriação e assimilação dos saberes culturais. O instrumento de análise de dados que foi aplicado é a análise de conteúdo preconizada por Bardin (2004). Na análise de conteúdo, não é só o conteúdo em si das comunicações que interessa, mas procura-se atingir, por 
meio da mensagem aparente, o que esta tem a nos dizer sobre os significados de natureza sociológica, psicológica, histórica e cultural que envolvem o discurso.

Palavras-chave: Comunicação. Arte. Cultura. Mediação midiática.

\begin{abstract}
This article aims to communicate the results of the research on the influence of media in ways of seeing and producing artistic cultural knowledge in Curitiba, Paraná, Brazil. The analysis of newspaper Gazeta do Povo as preferred media for research and source approach with informants of this research. The concepts of communication, art and culture are worked in order to understand the interweaving that occurs through the mediation of media as well as understand the processes of signification and appropriation and assimilation of cultural knowledge. The instrument for data analysis that was applied is the content analysis proposed by Bardin (2004). Content analysis is not only the content of communications itself that matters, but seeks to achieve through the apparent message, what this has to say about the meanings of nature sociological, psychological, historical and cultural discourse involving.
\end{abstract}

Keywords: Communication. Art. Culture. Media mediation.

\title{
Introdução
}

Este artigo se propõe fazer uma reflexão sobre a influência das mídias nos modos de ver e produzir saberes de arte e cultura. Toma-se como ponto de partida o jornal Gazeta do Povo, veículo de grande circulação na cidade de Curitiba e no estado do Paraná. Assume-se a hipótese de que, por meio da mediação, no sentido de aproximar a informação do receptor, a mídia pode interferir nos modos de ver, perceber e produzir o saber artístico cultural, e na interação/comunicação entre arte, cultura e sociedade.

Parte-se do pressuposto de um primado midiático, pois, conforme argumenta Gonçalves (2007), os usos diferenciados da mídia têm a capacidade de engendrar novas referências para a produção de sentido na cultura e na arte.

A arte é um processo de representação e produção simbólica, uma área rica de conhecimento para se problematizar questões relacionadas à comunicação e à cultura contemporâneas. Proença (2007) afirma que a arte é um fenômeno cultural carregado de complexidade e que abre perspectivas para a criação e produção de processos comunicativos, na medida em que favorece processos subjetivos de veiculação/transmissão de valores e signos. Gombrich (1995) destaca também que arte e cultura têm uma relação inequívoca na construção de sentidos e significados, por isso, não se pode julgar a arte como superior ou inferior dentro de determinada cultura ou em comparação com outras, não existe arte com A maiúsculo. 
Considerando que a cultura, como argumenta Thompson (1995, p. 173), "comporta um conjunto de crenças, costumes, ideias e valores, bem como os artefatos, objetos e instrumentos materiais, que são adquiridos pelos indivíduos enquanto membros de um grupo ou sociedade", pode-se dizer que há realmente uma disseminação de um jeito de agir, pensar e valorar a arte que é comum entre os habitantes de determinada sociedade.

Empreende-se, para tanto, a investigação sobre a onipresença da mediação midiática na ordenação das relações de poder que se produzem nas experiências e registros materiais e imateriais. Mediação midiática são processos que se dão na comunicação humana mediados pelos meios de comunicação de massa, constituindo-se em instâncias de produção e de apropriação midiática que envolvem os sujeitos numa complexa rede comunicacional. Nossa hipótese é que a leitura de um jornal pode interferir nos saberes sobre e concepções de cultura e arte que circulam na sociedade e que dão origem a modos específicos de perceber e significar o mundo e a cultura, e de formalizar a experiência.

\section{Arte e cultura: do passado à modernidade líquida}

A discussão sobre cultura deve ter sempre como ponto de partida o fenômeno da arte (ARENDT, 2007), porque em relação à cultura a arte está aí para durar, e não fica, ou pelo menos não deveria ficar, sujeita à manutenção ou produção de necessidades pontuais de determinada sociedade.

No passado, as produções artísticas eram endereçadas a determinado público ou a uma classe social específica, e somente tais poderiam fruir desta obra. A cultura compreendia então um acordo planejado e esperado entre os detentores do conhecimento e aqueles considerados ignorantes, "um acordo unilateralmente endossado e efetivado sob a direção exclusiva recém-formada da classe instruída" (BAUMAN, 2013 , p. 13). Este era o projeto de cultura iluminista, recorda Bourdieu (2008), para quem a cultura em seu estágio homeostático era um instrumento a serviço da construção do Estado-nação e da manutenção do status quo, da reprodução monótona da sociedade e da manutenção do equilíbrio do sistema (BAUMAN, 2013).

A superação desse estágio de aparente equilíbrio e solidez da cultura se dá na passagem para a modernidade líquida. $O$ autor dessa expressão se explica,

uso a expressão modernidade líquida para denominar o formato atual da condição moderna, descrita por outros autores como pós-modernidade [...]. O que torna líquida a modernidade, e assim justifica a escolha do nome, é sua modernização compulsiva e obsessiva, capaz de impulsionar e intensificar a si mesma, em consequência do que, como ocorre com os líquidos, nenhuma das formas consecutivas de vida social é capaz de manter seu aspecto por muito tempo (BAUMAN, 2013, p.16).

Essa fluidez pode ser testemunhada no dia a dia quando se presencia a reposição, a cada mês, de novos modelos de carro, eletrodomésticos, aplicativos móveis, moda etc. Tudo se transforma em eventos feitos de efervescências passageiras, cria- 
das ou realizadas para o consumo. Consumo, aqui, entendido como "o conjunto de processos socioculturais nos quais se realiza a apropriação e os usos dos produtos" (GARCÍA CANCLINI, 1993 apud JACKS; ESCOSTEGUY, 2005, p. 57). Surgem novos tipos de arte que somam ao conceito de arte material o conceito de arte imaterial, fazendo com que aqueles lugares que antes davam estatuto de arte a um objeto se reinventem e revejam suas funções culturais. Tem sido o caso, por exemplo, dos museus.

A sociedade que vivia em um sistema estável, em que as pessoas estavam intimamente conectadas entre si, passa a viver uma complexidade social em que os indivíduos, antes socialmente isolados, passam a atuar em uma rede intrincada de estratégias e consequências que leva ao aumento da heterogeneidade e individualidade. É uma sociedade que já não exerce tanto controle sobre seus membros e cuja cultura escapa dos ideais iluministas de usá-la como instrumento de controle. Surge desse contexto o que se conhece como sociedade de massa, cujo significado não diz respeito à sua extensão grande ou pequena, mas ao relacionamento existente entre indivíduos e a ordem social que os rodeia (DEFLEUR; BALL-ROKEACH, 1993).

Essa sociedade atual, líquida e consumista, é característica da sociedade de massas que, segundo Arendt (2007), não precisa de cultura, mas de diversão, e na qual os produtos oferecidos pela indústria de diversão são consumidos exatamente como quaisquer outros bens de consumo. Essa ideia é confirmada por um dos entrevistados, que afirma: "Para mim, o que não me diverte não é arte" (Entrevistado A5).

Para Santaella (2003), o conceito de cultura de massa é um legado da era industrial. Essa cultura originou-se no jornal juntamente com o telégrafo e a fotografia. Mas coube à TV consolidar a ideia do mass media e da sociedade de massa. De acordo com a autora, depois dos anos 1970, a cultura de massas deu lugar à cultura das mídias com o surgimento de novas tecnologias como fax, videocassete, TV a cabo, videogames, e de fenômenos como a segmentação de programas de rádio para públicos específicos e as revistas especializadas. Por fim, observa que "não há linearidade na passagem de uma era cultural para a outra, pois elas se sobrepõem, misturam-se, criando tecidos culturais híbridos e cada vez mais densos" (SANTAELLA, 2003, p. 81).

O que emerge desse contexto de uma modernidade líquida é uma cultura cuja função é criar constantemente outras tantas necessidades, e manter as que já existem. Dessa cultura, assim entendida, a sociedade se torna consumidora e quer que sejam produzidos artefatos/obras/objetos que a satisfaçam.

Arendt (2007), porém, discorda dessa posição consumista da cultura e da arte, e argumenta que o objeto cultural é feito para durar, e a durabilidade é o oposto da funcionalidade. É o caso da obra de arte, que é um objeto cultural não para o uso/consumo, mas para a fruição, para a permanência. Para a autora, uma catedral, por exemplo, pode servir culturalmente às necessidades de uma comunidade religiosa, mas a beleza de sua arquitetura não pode ser explicada por essa necessidade religiosa e transcende quaisquer funcionalidades.

A cultura sempre será ameaçada, quando

todos os objetos e coisas seculares, produzidos pelo presente ou pelo passado, são tratados como meras funções para o processo vital da sociedade, como se aí estivessem somente para satisfazer alguma necessidade - e nessa funcionaliza-

Rev. Estud. Comun., Curitiba, v. 15, n. 36, p. 79-89, jan./abr. 2014 
ção é praticamente indiferente saber se as necessidades em questão são de ordem superior ou inferior (ARENDT, 2007, p. 261-262).

Gonçalves (2007) afirma que, se a arte se apóia na narrativa da duração, ela poderia produzir experiências com a comunicação no nível da criação e do rearranjo dos códigos sociais. Para o autor, a arte pode realizar um trabalho de experimentações com elementos da cultura e da sociedade, seja refletindo, reforçando ou problematizando os seus valores e suas crenças. O Festival de Teatro de Curitiba é bom exemplo dessas experimentações. O Festival acontece todos os anos, entre os meses de março e abril, e é vivamente esperado por todas as pessoas e grupos ligados ao setor artístico da cidade. Seu principal objetivo é promover o acesso à cultura e à arte de modo geral. Contudo, outros fatores também culturais impedem a participação de boa parte cidadãos: falta de transportes adequados, falta de divulgação abrangente fora do nicho central de Curitiba, falta de conhecimento do valor da arte e da riqueza cultural da humanidade se tornam óbices para o acesso ao evento e, por conseguinte, à cultura e à arte.

Esse breve panorama da visão da cultura e da arte nas sociedades é fundamental para compreender a mediação dos meios de comunicação na elaboração/reelaboração na produção de saberes e nos processos de recepção e de significação. Os saberes referidos são os discursos e as informações que circulam na sociedade que constroem, desconstroem e se refazem por meio de interpretações, reinterpretações e significações da cultura e da arte.

\section{Comunicação, arte e cultura: construção de significados}

Como situar a comunicação nesse contexto? Assim como houve, na sociedade, uma mudança nas formas de relações entre os indivíduos, a arte e a cultura, houve também uma mudança na forma como os meios de comunicação medeiam as informações e os discursos que veiculam.

DeFleur e Ball-Rockeach (1993) propõem alguns princípios para se compreender como os veículos de comunicação de massa ajudam a entender como a mídia desempenha um papel na construção social de significados. O primeiro princípio trata da memória humana que favorece a aquisição do conhecimento; o segundo diz respeito ao conhecimento que existe sob a forma de conceitos, isto é, estruturas de significados lembradas pelos sujeitos; o terceiro se refere aos conceitos que podem ser criados por uma pessoa, seja por contato sensório com vários aspectos da realidade, seja pela interação simbólica em uma comunidade de linguagem; o quarto considera a linguagem vista como um conjunto de símbolos que ajustam significados; por fim, os símbolos e convenções da linguagem combinados e usados por determinadas pessoas que modelam sua percepção de, interpretação de, e conduta para com seu mundo físico e social.

Tudo isso interfere na circulação dos discursos, pois, segundo Lippmann (apud DEFLEUR; BALL-ROKEACH, 1993, p. 279), a imprensa influencia fundamentalmente nas formas como as pessoas agem, isto é, as pessoas não agem baseadas naquilo que está ocorrendo, mas "naquilo que imaginam ser a situação real conseguida de descrições fornecidas pela imprensa". 
A mídia de modo geral tem papel relevante nas formas com que a sociedade constrói seus significados, interferindo inclusive no imaginário nas pessoas sobre diferentes assuntos.

A mídia, pois, tem importantes influências em nossa linguagem e seus significados. Isso de várias maneiras. Ela estabelece novas palavras com significados a elas ligados; dissemina o significado de termos existentes; substitui significados antigos por outros novos; acima de tudo, oficializa convenções de significado existentes para o vocabulário de nossa linguagem (DEFLEUR; BALL-ROKEACH, 1993, p. 287).

O conjunto de crenças e valores que comporta a cultura envolve a arte de uma aura de interpretações e significações que a todo o momento são reelaborados por meio de discursos e de um fazer artístico criativo e produtivo.

Gonçalves (2007) tem desenvolvido pesquisa sobre a relação entre cultura, comunicação e arte contemporânea na cidade do Rio de Janeiro e de que modo elas têm penetrado os modos como se relacionam. Segundo este pesquisador, o uso que os artistas têm feito das mídias interferem também no imaginário dos observadores, que concebem conceitualmente a sua relação com a cidade, em um inusitado diálogo com a arte contemporânea. Nesse sentido, afirma ele, é relevante que se visite a relação o que os locais mantêm com as mídias que referenciam a arte e a cultura, para fomentar releituras de discursos e práticas sociais ligadas à constituição dos modos de vida, jogos de poder e criação de novas condições para a produção e o convívio com a diferença.

Pode-se dizer que há um "midiacentrismo", conforme salienta Gonçalves (2007), por causa do caráter fortemente veiculativo, em que os meios e a transmissibilidade tendem a constituir o fim dos processos comunicacionais, privilegiando a profusão da informação, a supervalorização da tecnologia midiática e a interatividade como se fossem qualidades positivas em si mesmas. A relação entre mídia, cultura e arte parecem depender de uma super comunicação de fluxos instantâneos para a criação de um saber cultural, ou ainda, para constituir relação entre cultura e arte.

Para Deleuze (1998), é preciso criar linhas que permitam escapar daquilo que está posto, para encontrar novas perspectivas, novos formas de dizer, de ver e fazer arte e cultura. "A produção de arte em uma sociedade sempre esteve intimamente ligada às condições de possibilidades de discurso e percepção existentes nela", afirma Gonçalves (2007, p. 6), pois a experiência de ver e falar é introduzida historicamente e pode ser situada na relação mesma entre saber e poder no processo comunicacional da cultura.

\section{Arte e cultura na cidade de Curitiba: a mediação midiática}

A cidade de Curitiba, capital do Estado do Paraná, foi fundada em 1693 e, atualmente, segundo dados do IBGE/censo 2010, conta com uma população de 1.746 .896 habitantes. Segundo informações divulgadas pelo site da Prefeitura, Curitiba tem o Índice de Desenvolvimento Humano (IDH) elevado em relação ao restante do país: 0,856. Em 2003, recebeu o título de Capital Americana da Cultura, pela Organização 
dos Estados Americanos (OEA). Esse título é o resultado dos investimentos realizados na cidade desde os anos 1970, com a criação da Fundação Cultural de Curitiba e inauguração do teatro Paiol, antigo paiol de munição do exército, reformado para fins artísticos culturais. Esse reconhecimento da cidade, como afeita ao investimento cultural, fez com que ela ficasse conhecida e reconhecida como referência para todo o país.

Com esta pesquisa, procura-se perceber por meio do encontro com os cidadãos curitibanos como eles constroem seus saberes artísticos e culturais. Toma-se como ponto de partida para a pesquisa o acompanhamento do jornal Gazeta do Povo, sobretudo o "Caderno G", que trata da agenda artísticocultural de Curitiba. Acompanhou-se o jornal, diariamente, de agosto a novembro de 2013, assinalando as principais chamadas que o jornal propôs. Buscouse os principais temas divulgados pelo "Caderno G" para estabelecimento de seu público. De acordo com a análise de conteúdo proposta por Bardin (2004), fez-se uma primeira classificação, para organizar todo o material selecionado. Limitou-se a análise aos oito primeiros temas mais divulgados nos meses acompanhados: show, com 177 publicações; cinema, com 171; literatura, com 155; música, com 117; teatro, com 98; arte, com 70; televisão, com 49; e dança, com 15. Dentro dessas divisões, existem ainda subdivisões como cinema nacional, música internacional entre outros.

O jornal é um veículo de comunicação de massa, portanto, segundo DeFleur e Ball-Rokaech (1993), influencia os indivíduos em suas ações, quando estes têm de decidir o que comprar, o que vestir e o que ver, além de interferir nas decisões sobre programas de divertimento, como ir ao cinema ou ouvir música com a família ou amigos. Os autores vão mais longe e afirmam que as mídias de massa influenciam inclusive a compreensão que o sujeito tem de si mesmo, assim como suas formas de ver e interpretar o mundo. Das 113 pessoas entrevistadas, 62 afirmaram que já foram influenciadas pelas noticias/divulgações do jornal Gazeta do Povo.

Berger (1977, p. 55) salienta que "as comunicações de massa não deixam de dar impulsos, sentimentos e esboços de estruturas". A comunicação de massa busca atingir o público de forma geral, e ao atingi-lo deve impactar de forma que todos se sintam parte de determinada notícia. Por isso, as notícias são massificadas, buscando um padrão que contemple a maioria das pessoas dessa sociedade. Pode-se, pois, caracterizar que o jornal Gazeta do Povo influencia a sociedade curitibana, fazendo uso das notícias em massa para provocar o impulso a que os leitores participem em determinados eventos veiculados pelo jornal.

Foram entrevistadas pessoas ligadas à área cultural de Curitiba para saber o posicionamento acerca da influência das mídias locais na produção de saberes culturais. Percebeu-se que há certo descontentamento com o pouco incentivo financeiro para colocar em circulação outros veículos que poderiam ajudar muito mais na divulgação da cultura local. Um dos entrevistados afirmou: "temos em Curitiba outros veículos menores de comunicação com o público curitibano, que valorizam muito mais a nossa cultura, mas infelizmente as mídias de massa engolem esses pequenos veículos, impedindo que as pessoas tenham outras fontes menos viciadas" (Entrevistado A1). Outro entrevistado argumentou que "há uma 
convenção a ser seguida, e quem não a segue está praticamente fora do circuito. Para quem trabalha com produção cultural, isso não pode acontecer. O jeito é aceitar" (Entrevistado A2).

A arte é um campo de produção simbólica, afirma Gonçalves (2007), e não pode estar sujeita, assim como a cultura, a fluxos instantâneos e padronizadores de um saber cultural. No encontro com as pessoas na rua, ao serem perguntados sobre questões de arte e cultura, elas sempre lembravam que, quando possível, iam ao cinema e/ou frequentavam os espetáculos promovidos na rua XV de novembro e no Largo da Ordem. Quanto ao modo como eles ficam sabendo desses shows: "meu amigo ouviu pelo rádio"; "eu vi na TV"; "eu li no jornal". Essas informações circulam e conseguem alcançar o grande público. É nesse campo que se dá o jogo de saber-poder da mídia. Poder que, segundo Deleuze (1992), está informalmente presente nas relações e vai construindo discursos por meio da mediação das mídias.

As mesmas informações transitam de uma mídia a outra, sob diferentes aspectos e linguagens, partindo de rádios e televisão para revistas e outros meios, podendo se transformar em documentários, filmes e livros. Vários livros foram vendidos aos milhares depois de terem sido transformados em filmes produzidos de preferência pelo entretenimento hollywoodiano (SANTAELLA, 2003).

As pessoas, muitas vezes, não identificam os monumentos, a arquitetura, as esculturas como obras de arte. Para muitos deles, arte é aquilo que está nos museus. Contudo, $82 \%$ dos que foram abordados nas ruas disseram que nunca estiveram em um museu da cidade e não estiveram dentro de um teatro. Pode-se inferir a partir desses dados a confirmação de que "Show" e "Cinema" são as categorias mais divulgadas no jornal Gazeta do Povo. Cabe lembrar que o jornal serve de referência também para programas de rádio, baseados na agenda do jornal para divulgar os espetáculos.

Um evento muito comentado pelos entrevistados é a Virada Cultural do Paraná, que envolve onze municípios do Estado. O objetivo da Virada é reunir as pessoas por meio da motivação cultural dentro de toda a sua diversidade. $O$ efeito é muito positivo e há participação de bom público, sobretudo de jovens. A questão é que tanto a Virada Cultural quanto o Festival de Curitiba têm um tipo de aporte e organização que não alcançam os bairros ou as cidades da região metropolitana. São sempre as mesmas pessoas atingidas por esses eventos, e não existe um projeto do mesmo porte que se ocupe dos outros grupos, das outras áreas.

O processo comunicativo que se dá nesses eventos, ou antes deles, a partir da mídia, provoca novas formas de interação, que vão além do tempo e do espaço, pois baseia-se numa dissociação entre o momento e o lugar da produção e o da recepção. Trata-se aqui de produção de formas simbólicas que serão direcionadas diferentemente para os que não participam, pois preferem, por exemplo, acompanhar as atividades culturais pela TV, e aos que participam do evento.

O encontro entre arte e cultura em Curitiba é rico, sem dúvida, mas o acesso a toda essa riqueza pelo povo paranaense, mormente o curitibano, ainda é carente de formas de mediação. O jornal Gazeta do Povo é veículo de grande abrangência, mas ainda inferior ao número de pessoas que poderiam ter acesso às informações por meio deste jornal.

Rev. Estud. Comun., Curitiba, v. 15, n. 36, p. 79-89, jan./abr. 2014 
No entanto, pode-se dizer que a complexa relação entre comunicação e cultura percebe e reconhece o papel dos diversos atores sociais nela implicados. Atores entendidos, segundo Castro et al. (2000), como actantes, como pessoa ou como entidade, como forças sociais produtoras de bens simbólicos. "Dentre esses atores, quer-se destacar, no caso específico das mídias, um actante poderoso e externo a ela como matéria física: os públicos" (CASTRO et al., 2000, p. 105).

No mundo contemporâneo, a comunicação exerce um papel fundamental e central com a presença generalizada das mídias. O contato com os produtos midiáticos e as convergências das mídias as informações chegam quase que de maneira síncrona de norte a sul do país. Tal atuação influencia de muitas maneiras na recepção e na significação dos saberes culturais. Uma pessoa perguntada sobre o que ela pensa da cultura norte-americana, ela provavelmente vai recorrer às séries e programas de TV para dizer como eles são, o que comem ou como se vestem.

As mídias difundem um jeito de ver e interpretar o mundo que influencia na visão de mundo, de natureza, de juventude, de infância, de arte e de cultura que as pessoas constroem. Seria também o caso de verificar o sentido contrário: como a sociedade e seus diferentes grupos influenciam as mídias nos aspectos da cultura e da arte. Mas isso foge ao propósito deste artigo.

\section{Conclusão}

Este artigo buscou mostrar os resultados de uma pesquisa sobre a influência da mídia nos modos de ver e de produzir saberes artísticos e culturais em Curitiba. O entrelaçamento entre comunicação, arte e cultura expõe uma questão que se procura demonstrar sobre o papel de divulgador e difusor de agenda que o jornal exerce. Ao produzir essa agenda e selecionar aquilo que será divulgado, as mídias não são neutras e as informações são carregadas de significações e sentidos dados a priori. O interlocutor, ao receber essas informações, recebe também uma a carga de significações que vai povoar o imaginário dos leitores, configurando-se em saberes, concepções e modos de ver o mundo engendradas pelas mídias.

A produção/construção de saberes artísticos culturais na cidade de Curitiba constitui-se em um rico acervo de conhecimentos, significações, entendimentos, realizações empreendidos pelos seres humanos nos processos de comunicação e interação. As mídias, sejam emissoras de televisão, jornais, rádios ou as novas tecnologias de informação e comunicação, ampliam as possibilidades de enriquecimento deste acervo.

No entanto, não se pode delegar aos meios de comunicação, apenas, a responsabilidade da construção desses saberes, mas deve-se acompanhar, compreender e posicionar-nos sempre que a mediação midiática impedir ou obscurecer a capacidade de o sujeito criar e recriar significados, a capacidade de fazer suas próprias experiências.

Arte e Cultura são manifestações eminentemente humanas que não estão relacionadas ao consumo, ao uso e suprimento de necessidades da vida humana, 
mas são realizações que devem durar, transcender tempos e espaços, reinventando produtiva e criativamente as possibilidades de comunicação.

Na modernidade líquida, a arte contemporânea é a arte da comunicação como argumenta Cauquelin (2005). Essa disposição para a comunicação deve ser capaz de criar novas formas de significação, de sensibilização e de fruição, abrindo perspectivas para novas experiências estéticas, de comunicação e de entrelaçamento com o aparato midiático. Dessa forma, o indivíduo enriquece seu acervo e abre novos pontos de fuga, de escape para novas descobertas no campo das artes e da cultura locais.

\section{Referências}

ARENDT, H. Entre o passado e o futuro. 6. ed. São Paulo: Perspectiva, 2007.

BARDIN, L. Análise de conteúdo. 3. ed. Porto: Edições 70, 2004.

BAUMAN; Z. A cultura no mundo liquido moderno. Rio de Janeiro: Zahar, 2013.

BERGER, R. Arte e comunicação. São Paulo: Paulinas, 1977.

BOURDIEU, P. A distinção: crítica social do julgamento. São Paulo: Edusp; Porto Alegre: Zouk, 2008.

CAUQUELIN, A. Arte contemporânea: uma introdução. São Paulo: Martins Fontes, 2005.

CASTRO, M. L. D. et al. Mídias e processos de significação. São Leopoldo: Unisinos, 2000.

DEFLEUR, M.; BALL-ROKEACH, S. Teorias da comunicação de massa. Rio de Janeiro: Jorge Zahar, 1993.

DELEUZE, G. Conversações. Rio de Janeiro: 34, 1992.

DELEUZE, G. Diálogos. São Paulo: Escuta, 1998.

GOMBRICH. E. H. A História da Arte. Trad. Álvaro Cabral. Rio de Janeiro: LTC, 1995.

GONÇALVES, F. N. Comunicação, cultura e arte. Contemporânea, v. 5, n. 8, 2007. Disponível em: <http://www.contemporanea.uerj.br/pdf/ed_08/01FERNANDO.pdf>. Acesso em: 1 을aio 2013.

JACKS, N.; ESCOSTEGUY, A. C. Comunicação e recepção. São Paulo: Hacker, 2005.

PROENÇA, G. História da Arte. São Paulo: Ática, 2007. 
SANTAELLA, L. Cultura e artes do pós-humano. São Paulo: Paulus, 2003.

THOMPSON, J. B. Ideologia e cultura moderna. 5. ed. Petrópolis: Vozes, 1995.

Recebido: 10/02/2014

Received: 02/10/2014

Aprovado: 14/03/2014

Approved: 03/14/2014

Publicado: 30/05/2014

Published: 05/30/2014 